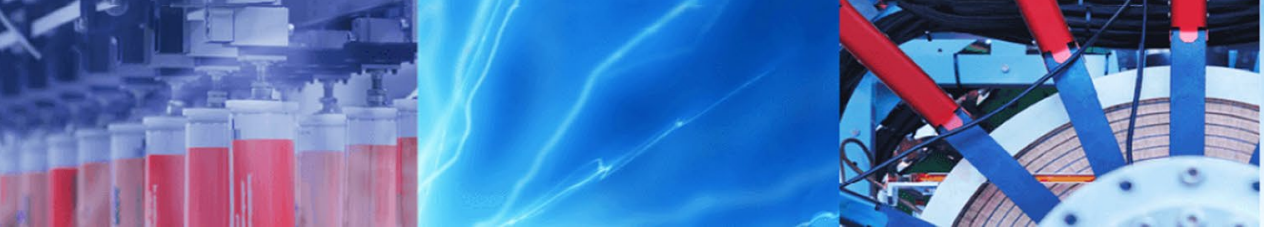

Research Article

\title{
The influence of textile materials on flame resistance ratings of professional uniforms
}

\author{
Marcia Cristina Silva-Santos ${ }^{1}$ (D) $\cdot$ Joaquim Jorge Peixoto ${ }^{2}$ (I) $\cdot$ Raul Fangueiro $^{2}$ (D) Fernando Gasi $^{3}$ (D) \\ Julia Baruque-Ramos ${ }^{1}$ (i)
}

Received: 16 June 2019 / Accepted: 15 November 2019 / Published online: 21 November 2019

(c) Springer Nature Switzerland AG 2019

\begin{abstract}
This study compares the flame speed of different textile materials employed in professional uniforms. Five different garments of aeronauts' uniforms were analyzed (totaling 200 specimens submitted to flammability tests). Plain weaves and twill weaves composed by $100 \%$ CO; $100 \%$ PES; $67 \%$ PES/33\% CO; $50 \%$ PES $/ 50 \%$ WO; and $55 \%$ PES/45\%WO were analyzed in the warp and filling directions. The flame speed of each material was determined, and differences in the flame propagation of the fabrics were identified. The lowest flame speed occurred for the material $50 \% \mathrm{PES} / 50 \%$ WO plain weave and weft direction $(0.742 \pm 0.140 \mathrm{~m} / \mathrm{s})$. The highest flame speed was $3.698 \pm 1.806 \mathrm{~cm} / \mathrm{s}$ for the material $67 \% \mathrm{PES} / 33 \% \mathrm{CO}$, plain weave and filling direction. Future experiments for reducing the fabric flammability of the uniforms could be related to more closed fabric constructions; mixtures with synthetic fibers to add functionality; changing the direction of the fabric; and changing the weight and torsion of its constituent yarns.
\end{abstract}

Keywords Flammability · Textile $\cdot$ Uniform $\cdot$ Aeronaut $\cdot$ Civil aviation $\cdot$ Statistical analysis of factors

\section{Introduction}

Flammability is explained by Lewin [1] and Sinclair [2] as the tendency of a material to ignite and burn with a flame creating a fire risk situation. In textile materials, it represents the easiness with which the fabric is capable of being ignited and how effectively it burns, considering that the response to the heat depends mainly on its chemical composition. Thus, they can be classified as thermoplastics, which soften and melt above certain temperatures and non-thermoplastics, which tend to carbonize and embrittle at high temperatures.

In addition, textile combustibility is related to the rate at which the flame is able to propagate. Exothermic reactions are triggered when the ignition temperature of the fabric is reached. The high risk of fire attributed to the fabrics is due to their large area surface and the ease of access to the environmental oxygen $[3,4]$.

Fan and Lau [5] consider the influence of the textile material on the burning mechanism as one of two components of the fire quadrilateral: the fuel and the oxidizing agent (oxygen). The type of fiber such as its chemical composition and the possible application of flame-retardant finishes play important roles as fuel. The structure of the fabric, represented by its ligament, yarn density, covering factor and weight, is related to the air/oxygen ratio on the fabric surface and its action as oxidizing agent.

One of the factors for the differentiation of fabric flame speed is the fiber material composition. Fabrics made from untreated natural fibers such as cotton, linen, silk, present easy ignition and rapid flame propagation. Fabrics made

$\triangle$ Marcia Cristina Silva-Santos, 333marciacristina@gmail.com | ${ }^{1}$ School of Arts, Sciences and Humanities, University of São Paulo, Av. Arlindo Bettio, 1000, São Paulo, SP 03828-000, Brazil. ${ }^{2}$ University of Minho, Alameda da Universidade, 4800-058 Guimarães, Portugal. ${ }^{3}$ Federal University of ABC, Alameda da Universidade, s/n - Anchieta, Sao Bernardo Do Campo, SP 09606-045, Brazil. 
from synthetic fibers and, however, resist ignition, but the textile material melts $[6,7]$.

Another flammability indicator is the limiting oxygen index (LOI), which represents the minimum concentration of oxygen, expressed as a percentage, that will support combustion of a polymer. In this way, the lower LOI, the easier the fiber burns and this index can be applied to almost all fibers [8].

The textile fibers are selected based on their characteristics, and the most appropriate ones are employed in the final product. Some examples of these characteristics are: durability, fineness, abrasion resistance, impermeability, etc. [9]. The fibers are transformed into yarns and employed in the manufacture of flat woven, knitted or nonwoven fabrics [10]. Among other factors, the chemical nature of the fibers is related to a very large variation in the flammability of the fabrics, being very flammable in the cellulosic fibers and in the common synthetic fibers [11].

Until the eighteenth century, the main fibers employed in domestic production were those of natural origin, such as wool, cotton, silk, hemp and flax. The first manufactured fiber, called regenerated cellulose fiber (rayon or viscose rayon), was developed at the end of the nineteenth century, but only in the twentieth century began its industrial production. The development of chemical fibers based on petroleum products started in the late 1930s and industrial production launched during World War II [12].

Flat woven fabrics are non-continuous materials with anisotropic mechanical properties. Besides the characteristics of the constituent fibers, the performance of the textile materials depends on the weaving mechanics and geometry [13]. The weaving pattern influences the maximum density through the intersecting relationship of warp and weft yarns as well as weight and thickness [9].

In addition, most fabrics are flammable within certain limits. However, this does not mean that the clothes inflame during normal wearing. On the other hand, the number of fatal accidents involving fire in clothing is greater than cases involving furniture [14].

Uniform is emblematic, since it legitimizes and indicates the status of wearer, but also suppresses individuality. It is seen as a barrier, which ensures that each member of the organization will act according to their function and be perceived as important parts of their professional identity $[15,16]$. In military sector, besides the status, it plays an important role in the process of transforming the inexperienced and untrained recruit into a member of the military force [17].

Professional uniforms are not required for all functions. It is a company's choice in order to represent its brand considering the symbolic value of the uniform. The development of professional uniform garments generally takes into account the aesthetic characteristics and cost.
For functions requiring uniform such personal protective equipments (PPE), the specifications for the textile material are regulated. In this context, the collections developed for uniforms of aeronauts (workers on board the aircrafts) do not consider their acting also as flight safety agents, which eventually could be subjected to the combat of fires on board [8].

The objective of this study was the analysis of the flammability (flame speed) of textile materials employed in the manufacturing of professional uniforms of aeronauts (flight crew) of Brazilian airlines.

\section{Materials and methods}

\subsection{Specimens}

During the period from February 2016 to March 2017, uniforms of aeronauts were acquired by donations. The companies did not allow the disclosure of brand's name. In this way, they were named as companies " $A$ " and "B." A preliminary analysis of these samples (P1 to P8) indicated the following structures and materials: Airline company "A" - (P1) 100\% polyester (PES) twill fabric female shirt; (P2) $100 \%$ PES plain fabric female shirt; and (P3) $67 \%$ PES/33\% cotton (CO) twill fabric male shirt; Airline company "B"(P4 and P5) 67\% PES/33\% CO plain fabric male shirts; (P6) $55 \%$ PES $/ 45 \%$ wool (WO) male coat; (P7) 50\% PES/50\% WO male trousers; and (P8) 55\% PES/45\% WO male coat.

For preliminary analysis, professional fabrics (T1-100\% $\mathrm{CO}$, and $\mathrm{T} 2-67 \% \mathrm{PES} / 33 \% \mathrm{CO}$ ) were purchased on the market for preliminary destructive testing, preserving professional uniforms material, until the improvement of the methods.

Information on the material of the fibers was collected from the label tags. In addition, FTIR (Fourier-transform infrared spectroscopy) tests were carried out to confirm such information.

Each garment was photographed, and an identification datasheet was created aiming the control of the materials after the disassembly of each apparel. It is observed that the uniform colors are related to the visual identity of the airline. In this way, the clothes were photographed in black and white. At this stage, it was possible to observe the manufacturing methods employed for their production. The visual characteristics of the aeronaut uniforms are shown in Figs. 1 and 2.

\subsection{Fiber material: label tags and FTIR}

A visual analysis of the uniforms and fabrics was performed, and the fabric structure (plain or twill) was verified. In addition, the information of the textile composition 


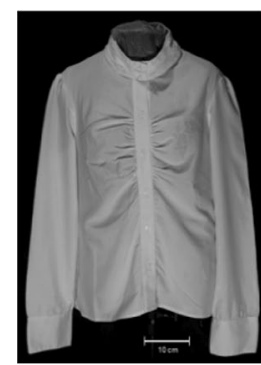

(a)

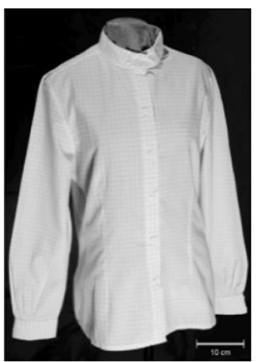

(b)

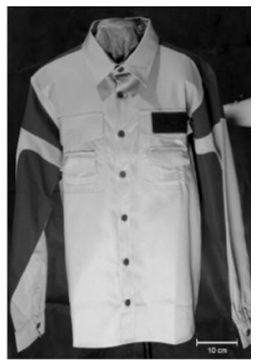

(c)
Fig. 1 Uniforms of Airline company "A": a P1-100\% PES twill fabric female pleats shirt; b P2-100\% PES plain fabric female plaid shirt; c P3-67\% PES/33\% CO twill fabric male maintenance service shirt. Scale $10 \mathrm{~cm}$

was obtained from the product label tag, since such information is obligatory for textile apparels made in Brazil (ABNT NBR NM IS 3758:2013) [18].

In order to confirm the textile materials stated on the label tags, a sample of at least 5 grams of the fabric of each uniform (P1 to P5) and of the fabrics (T1 and T2) was analyzed by spectroscopy in the medium infrared region (700 to $4000 \mathrm{~cm}^{-1}$ ) in FTIR equipment Thermo Avatar 370 with ATR (Nicolet, USA) and Omnic software, version 4.1 in comparison with standards stored in the equipment library [19].

\subsection{Weaving pattern}

The determination of the weaving pattern (plain, twill or satin), that is, the interweaving of warp and filling (or weft) yarns of the fabrics (T1 and T2) and the fabrics of parts of the uniforms (P1 to P8), followed the protocol established by standard ABNT 12996: 1993-Textile material-Determination of basic weaves-Method of test [20]. A pick glass, $10 \times$ visualization was employed. Subsidiarily, the Portuguese Standard NP 4114:1991-Textile:
Construction. Methods of analysis [21] and ISO 7211-1: 1984-Textiles-Woven fabrics-Construction-Methods of analysis-Part 1: Methods for the presentation of a weave diagram and plans for drafting, denting and lifting [22] were also applied.

\subsection{Yarn density (thread count)}

The yarn density (thread count) indicates how many warp or filling yarns are aligned per centimeter in the fabric. The test was carried out according to the standard NBR ABNT 10588:2015-Woven-Determination of density yarn [23]. This is a necessary information for calculating cover factor. A pick glass, $10 \times$ visualization was employed. Subsidiarily, the Portuguese Standard NP EM 1049-2:1995-TextilesWoven fabrics-Construction-Methods of analysis-Part 2: Determination of density of threads per unit length [23] and ISO 7211-2: 1984-Textiles-Woven fabrics-Construction-Methods of analysis-Part 2: Determination of number of threads per unit length [24] were also applied.

\subsection{Thickness}

The thickness measurement was performed according to the ABNT NBR 13371: 2005-Textiles materials-Determination of thickness [25]. The measurements in each sample were carried out in ten different points without damaging it. The portable analog thickness gauge (model 7321, Mitutoyo, Japan), $0.01 \mathrm{~mm}$ precision and 18 Pa pre-established clamp pressure, was employed.

\subsection{Weight}

The samples, measuring $100 \mathrm{~cm}^{2}$, were acclimatized according to the standards ABNT NBR ISO 139: 2005Textiles-Standard atmospheres for conditioning and testing [26] and ABNT NBR 12331:1991-Textile fibersConditioning conventional rate-Standardization [27].

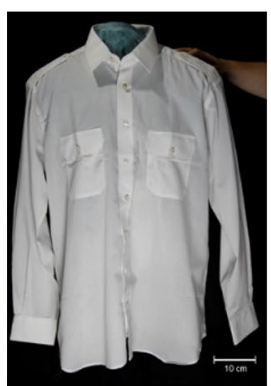

(a)

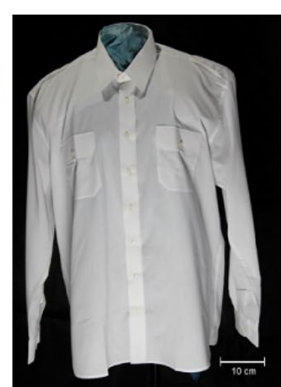

(b)

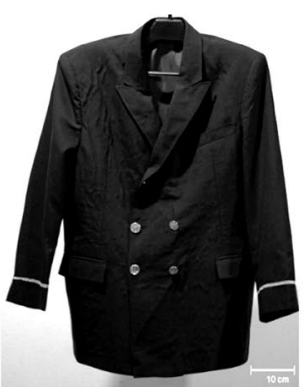

(c)

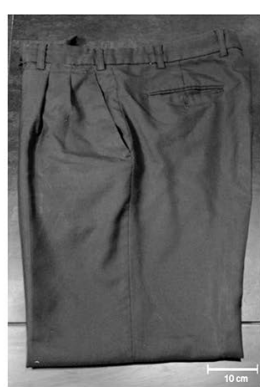

(d)

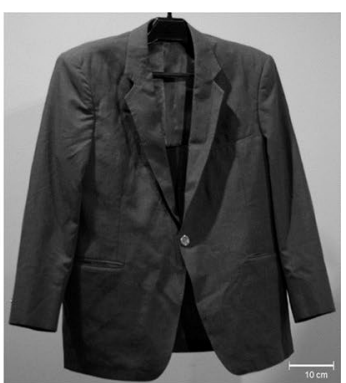

(e)

Fig. 2 Uniforms of Airline company "B": a, b P4 and P5-67\% PES/33\% CO plain fabric male shirts; c P6-55\% PES/45\% WO male coat; d P7-50\% PES $/ 50 \%$ WO male trousers; e P8- $55 \%$ PES $/ 45 \%$ WO male coat 
The minimum period consisted was $48 \mathrm{~h}$ at $20^{\circ} \mathrm{C}$ and $65 \%$ relative humidity in acclimatization cabin (Mesdan, model Climatest M250-RH, Italy). The samples were immediately weighed in an analytical balance (Sartorius, model ED 1245 , Germany) and the individual weights calculated according to

Weight $=\bar{M} \times 100$

$\bar{M}=$ Average of weights of samples measuring $100 \mathrm{~cm}^{2}(\mathrm{~g})$

\subsection{Linear density and crimp}

This test was performed according ISO 7211/5:1984 (Textiles-Woven fabrics-Construction-Methods of analysis-Part 5: Determination of linear density of yarn removed from fabric) [28] together the Crimp Test ISO 7211/3:1984 (Textiles-Woven fabrics-ConstructionMethods of analysis-Part 3: Determination of crimp of yarn in fabric) [29] employing the Crimp Tester Maillemetre. From each sample fabric, 11 warp and 11 filling threads were extracted. After conducting the pretension test and determining the load, each thread was weighed and the value of its linear density was determined in Tex (grams per $1000 \mathrm{~m})$.

\subsection{Thread twist}

The tests were carried out according to ISO 7211/4:1984Textiles-Woven fabrics - Construction-Methods of analysis-Part 4: Determination of twist in yarn removed from fabric [30]. For open-end 70-cm-length threads, twistronic device was employed (Mesdan, Italy). The thread is placed in the jaws of the equipment, causing its distortion and twisting, and the value is displayed on the electronic panel. For samples smaller than $70 \mathrm{~cm}$, twist tester from James H. Heal \& Co., Ltd., was employed.

\subsection{Yarn diameter calculation by Peirce geometric model}

Considering that the yarns are flattened in textile structure, it is necessary to correct this effect by Peirce's model. The calculation of the yarn diameter considered its linear density (weight per unit length) in Tex, the fiber density and the yarn packing factor according Eq. 2. According to Behera [31], this equation is applicable for many types of yarns with different types of fibers. The tabulated values of fiber density and the yarn packing factor can be found in Tables 1 and 2.
Table 1 Fiber density $\left(\mathrm{g} / \mathrm{cm}^{3}\right)$. Source: Behera and Hari [31]

\begin{tabular}{ll}
\hline Fiber & $P_{F}$ \\
\hline Cotton & 1.52 \\
Polyester & 1.38 \\
Wool & 1.32 \\
\hline
\end{tabular}

Table 2 Yarn packing factor. Source: Behera and Hari [31]

$d=\frac{\sqrt{T}}{280,2 x \sqrt{\emptyset \rho_{f}}}$

$d=$ yarn diameter $(\mathrm{mm}) ; T=$ linear density (Tex); $\rho f=$ fiber density $\left(\mathrm{g} / \mathrm{cm}^{3}\right) ; \emptyset=$ yarn packing factor.

For yarn made with fiber blending, it is necessary to calculate the (proportional) fiber density according to Eq. 3.

$\frac{1}{\bar{\rho}}=\sum_{1}^{n} \frac{p_{i}}{p_{f t}}$

$\rho=$ average of fiber densities; $p_{i}=$ weight fraction of umpteenth component; $p_{f t}=$ fiber density $\left(\mathrm{g} / \mathrm{cm}^{3}\right)$; $n=$ number of the mixture components.

\subsection{Cover factor}

For the calculation of the cover factor, the amount of warp and filling yarns, linear density as well as the yarn diameter is required. For each set of yarns, the product of yarn count (per inch) and yarn diameter (in inches) is less than one; then, theoretically open spaces will exist between the yarns. This ratio of the fabric surface occupied by the yarn to the total fabric surface is called the fabric cover factor, whose calculation is shown in Eq. 4 [32, 33].

$C=W \cdot d_{w}+F \cdot d_{f}-W \cdot F \cdot d_{w} \cdot d_{f}$

$C=$ cover factor; $W=$ warp threads per inch; $F=$ filling threads per inch; $d_{w}=$ warp yarn diameter (in inches); $d_{f}=$ filling yarn diameter (in inches).

\subsection{Flame speed}

The flame speed test was performed from the adaptation of the American standard CFR 1610 (Standard for the 
flammability of clothing textiles) [34]. The flame size was adjusted at $16 \mathrm{~mm}$ and was applied on the surface of the fabric, near the bottom edge for $3 \mathrm{~s}$ using propane gas and without forced exhaustion.

The flammability test cabin (Fig. 3) was built according the necessary adaptations to the objectives of this study. The assumptions for constructions are established in the standard 16CFR Part 1610:2018 - Standard for flammability of clothing textile [34]; ISO 6940:2004-Textile Fabrics-Burning behavior-Determination of ease of ignition of vertically oriented specimens [35]; ISO 6941:2003-Textile Fabrics-Burning behavior-Measurement of flame spread properties of vertically oriented specimens [36]; e NF G07-182-Textiles-Fire behavior-Measurement of flame spread properties of $45^{\circ}$ oriented specimensDetermination of flame spread rate [37].

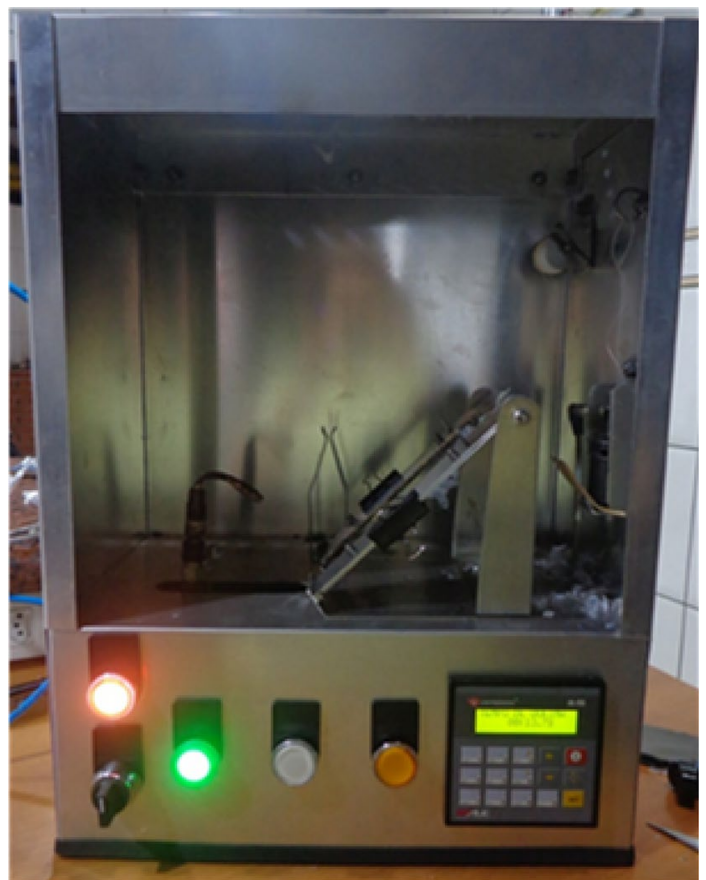

Fig. 3 Flammability test cabin built for the flame speed experiments
The construction of a flammability test cabin was because of the specificity of the small samples, the prioritization in the measurement of flame speed and the quantity of assayed samples, totaling 200 tests. The measurement system of this flammability cabin was statistically pre-validated according to the cited standards (data not shown).

For the fabric samples removed from the aeronauts' uniforms ( $P 1$ to $P 8), 20$ specimens were prepared in the dimensions of 55 by $155 \mathrm{~mm}$. Each sample was fixed to the frame and placed in the cabin with the inclination of $45^{\circ}$. The flame size, adjusted at $16 \mathrm{~mm}$, was applied to the fabric surface, close to the lower edge for $3 \mathrm{~s}$, employing propane gas and without forced exhaustion. The flame traversed the length of the fabric by $135 \mathrm{~mm}$ to the marked limit with the pendulum support line which, upon breaking, triggers the sensor and closes the time count on timer. As pretests, the same assay described was performed with fabric samples $\mathrm{T} 1$ and $\mathrm{T} 2$.

\subsection{Experimental design}

In the experimental design (Fig. 4) to verify the influence of the material of the fabric at the flame speed, the specimens were grouped by weave pattern (plain and twill) and direction (filling and warp). After that, it was possible established the hypotheses for the test, where $\mathrm{H} 0=$ all burning rate averages are the same for the tested materials (null) and $\mathrm{H} 1$ = at least one mean is different (alternative).

\subsection{Data analysis}

With data collected, a one-way analysis of variance (ANOVA) was performed. To verify the ANOVA assumptions [38], the Anderson-Darling tests were performed to verify the normality of the residual distribution and the Bartlett, Levene and Bonett tests to verify the homogeneity of the variances and the comparison of averages by the multiple comparisons test with the best, proposed by Hsu at the $5 \%$ probability level. When necessary, the Kruskal-Wallis nonparametric test was performed.

\begin{tabular}{|c|c|c|c|c|c|c|c|c|c|}
\hline $\begin{array}{c}\mathrm{T} 1 \\
100 \% \mathrm{Co}\end{array}$ & $\left(\begin{array}{c}\mathrm{P} 1 \\
100 \% \mathrm{PES}\end{array}\right.$ & $\begin{array}{c}\mathrm{P} 3 \\
67 \% \mathrm{PES} \\
33 \% \mathrm{CO} \\
\end{array}$ & $\begin{array}{c}\mathrm{T} 2 \\
67 \% \mathrm{PES} \\
33 \% \mathrm{CO} \\
\end{array}$ & $\left(\begin{array}{c}\mathrm{P} 2 \\
100 \% \mathrm{PES}\end{array}\right)$ & $\begin{array}{c}\text { P4 } \\
67 \% \text { PES } \\
33 \% \mathrm{CO} \\
\end{array}$ & $\begin{array}{c}\text { P5 } \\
67 \% \text { PES } \\
33 \% \mathrm{CO}\end{array}$ & $\begin{array}{c}\mathrm{P} 6 \\
55 \% \mathrm{PES} \\
45 \% \mathrm{WO} \\
\end{array}$ & $\begin{array}{c}\text { P7 } \\
50 \% \text { PES } \\
50 \% \text { WO }\end{array}$ & $\begin{array}{c}\text { P8 } \\
55 \% \text { PES } \\
45 \% \mathrm{CO}\end{array}$ \\
\hline \multicolumn{3}{|c|}{ Twill fabric } & \multicolumn{7}{|c|}{ Plain } \\
\hline $\begin{array}{l}\text { Warp } \\
n=30\end{array}$ & & $\begin{array}{c}\text { Weft } \\
n=30\end{array}$ & & $\begin{array}{l}\text { Weft } \\
n=70\end{array}$ & & & & $\begin{array}{l}\text { Warp } \\
n=70\end{array}$ & \\
\hline
\end{tabular}

Fig. 4 Experimental design 
These data were analyzed statistically using Minitab software (Minitab Inc., version 18-2017), available by Institutional Software Download System of the Information Technology Superintendence of USP.

\section{Results and discussion}

The FTIR analysis confirmed the information present in the label tags of all uniforms (data not shown).

The obtained results for all tests and calculations, expressed in material (CO-cotton, PES-polyester and WO-wool), weave (plain and twill), number of threads (by $\mathrm{cm})$, weight $\left(\mathrm{g} / \mathrm{m}^{2}\right)$, yarn density (Tex), twist (torsions $\left./ \mathrm{m}\right)$, yarn diameter (calculated by Peirce model), cover factor and flame speed (determined in direction of filling and warp) are presented in Table 3.

Taking in account a general analysis, for the evaluated fabrics in the flammability test, the lowest value was $0.742 \pm 0.140 \mathrm{~cm} / \mathrm{s}$. This result was obtained from ten tested fabric samples of $\mathrm{P} 7$ piece (male trousers-Airline company " $\mathrm{B}$ ") in the direction of the filling. The fabric composition is a blend of $50 \%$ wool and $50 \%$ polyester, $225.12 \pm 5.02 \mathrm{~g} / \mathrm{m}^{2}$ weight and $36.61 \pm 1.48$ Tex linear yarn density.

At the other extreme, the highest value was $3.698 \pm 1.806 \mathrm{~cm} / \mathrm{s}$. This result was obtained from ten tested fabric samples of P5 (male shirt-Airline company " $B$ ") in the direction of the filling. The composition is a blend of $67 \%$ polyester and $33 \%$ cotton, $108.72 \pm 2.39 \mathrm{~g} /$ $\mathrm{m}^{2}$ weight and $15.88 \pm 1.27$ Tex linear yarn density.

\subsection{Statistical analysis of the variables}

In order to evaluate the contribution of the factor studied, the analysis of variance (ANOVA) initially performed, which tests the hypothesis that the averages of two or more populations are equal. The hypothesis test for the comparison between the average flame speeds (response variable) in relation to the explanatory variables (material, weave, thread direction, weight, thickness, linear density and yarn diameter) was ANOVA one way for the verification of each variable influence in the result. However, it was not possible to validate the ANOVA one way with all the factors (explanatory variables) since the residues did not meet the assumptions of normal distribution and variance equality (data not shown).

In this way, it was opted to analyze the relationship of three explanatory variables ("direction," "material" and "weave") with the response variable "flame speed," by grouping the results from the physical tests performed on the fabrics with specific affinities, i.e., similar technical specifications.

The results were grouped by type of weave pattern (plain and twill) and direction (filling and warp) and verified the hypothesis of equality of averages of the response variable flame speed with respect to the material explanatory variable (100\% CO, 100\% PES, $67 \%$ $\mathrm{PES} / 33 \% \mathrm{CO}, 55 \% \mathrm{PES} / 45 \% \mathrm{WO}, 50 \% \mathrm{PES} / 50 \% \mathrm{WO})$.

A level of significance of $a=0.05$ was used in the analysis of ANOVA, representing a $95 \%$ confidence in the results. The $F$ statistic test was also calculated and compared with the critical tabulated value $\left(F_{C}\right)$. Thus, if the $F<F_{C}$, the null hypothesis is accepted. This indicates that there is at least one significant difference between the compared averages. The rejection or not of the null hypothesis can also be verified by the $p$ value. If the $p$ value is greater than $a=0.05$, the null hypothesis is accepted, since the evidence is not enough to affirm that there are significant differences between the analyzed averages [38]. Table 4 presents the results obtained with ANOVA analysis.

The analysis indicated the values for the $\mathrm{G} 1(F=271.74$, $\left.p=0.000, F_{C}=3.35\right), \mathrm{G} 2\left(F=44.04, p=0.000, F_{C}=3.35\right)$, $\mathrm{G} 3\left(F=311.79, p=0.000, F_{C}=3.23\right)$ and $\mathrm{G} 4(F=321.12$, $\left.p=0.000, F_{C}=3.23\right)$. In this way, for $\mathrm{G} 1, \mathrm{G} 2, \mathrm{G} 3$ and $\mathrm{G} 4$, the values of $\mathrm{F}$ test are greater than critical $\mathrm{F}\left(F<\mathrm{F}_{\mathrm{C}}\right)$ and $p$ value indicates there are sufficient evidences that not all the averages are equal when alpha is set at 0.05 . This means that is possible to state that there is at least one significant difference between the flame speed averages (Fig. 5).

In order to validate the ANOVA analysis, it is necessary to check the distribution and homogeneity of the residues. Anderson-Darling normality tests were performed for the residues and returned the following values for groups $\mathrm{G} 1$ $(p=0.115)$ and $\mathrm{G} 2(p=0.054)$. Then, with $p$ values greater than $a$, the hypothesis of the normal distribution of the residues is accepted. For the values of $\mathrm{G} 3(p<0.005)$ and $\mathrm{G} 4(p<0.005), p$ value was lower than $a$ and the hypothesis of normal distribution of residues was rejected. Additionally, Levene test was applied to confirm the homogeneity of the residue variance and returned the $p$ values for $\mathrm{G} 1$ $(p=0.059), \mathrm{G} 2(p=0.003), \mathrm{G} 3(p=0.000)$ and $\mathrm{G} 4(p=0.000)$.

It was verified that $\mathrm{G} 1$ indicates there is sufficient evidence that the variances are equal. In this way, the analysis of variance was validated and the alternative hypothesis was accepted at a significance level $a=0.05$ considering that there is difference in the flame speed between the tested materials.

The approach for the groups that did not meet the ANOVA assumptions was the nonparametric 


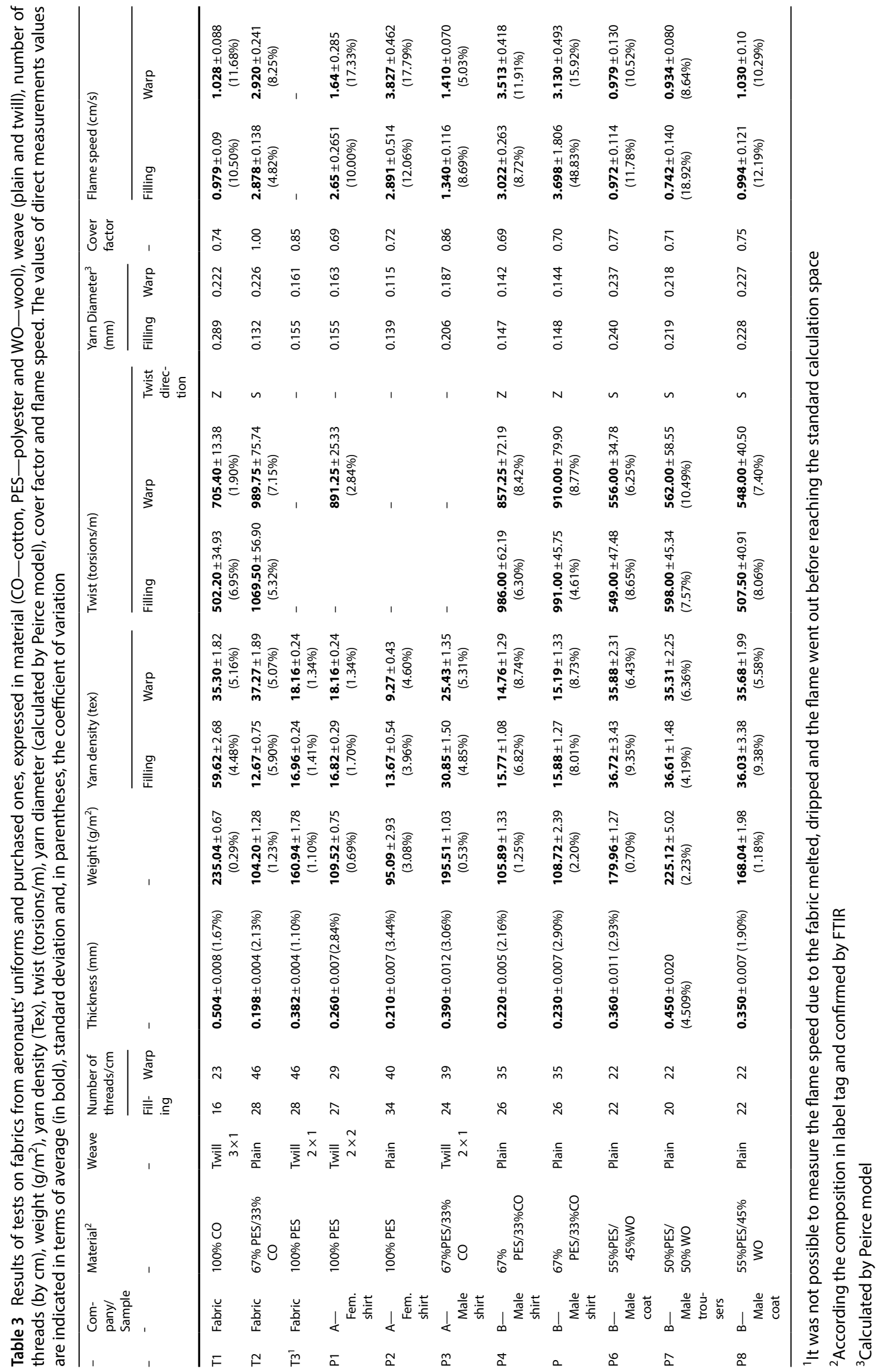


Table 4 Analysis of the influence of the fabric material (explanatory variable) on the flame speed (response variable) considering weave pattern (twill and plain) and direction (filling and warp)

\begin{tabular}{|c|c|c|c|c|c|}
\hline \multicolumn{6}{|c|}{ Analysis of variance } \\
\hline Source & $\mathrm{DF}^{\mathrm{a}}$ & Adj. SS ${ }^{b}$ & Adj. $\mathrm{MS}^{\mathrm{C}}$ & $F$ value & $p$ value \\
\hline \multicolumn{6}{|c|}{ Twill weave, filling direction-G1 } \\
\hline Material & 2 & 16.6807 & 8.34033 & 271.74 & 0.000 \\
\hline Error & 27 & 0.8287 & 0.03069 & & \\
\hline Total & 29 & 17.5093 & & & \\
\hline \multicolumn{6}{|c|}{ Twill weave, warp direction-G2 } \\
\hline Material & 2 & 2.8391 & 1.41957 & 44.04 & 0.000 \\
\hline Error & 27 & 0.8703 & 0.03224 & & \\
\hline Total & 29 & 3.7095 & & & \\
\hline \multicolumn{6}{|c|}{ Plain weave, filling direction-G3 } \\
\hline Material & 2 & 61.498 & 30.7492 & 311.79 & 0.000 \\
\hline Error & 47 & 4.635 & 0.0986 & & \\
\hline Total & 49 & 66.134 & & & \\
\hline \multicolumn{6}{|c|}{ Plain weave, warp direction-G4 } \\
\hline Material & 2 & 65.776 & 32.880 & 321.12 & 0.000 \\
\hline Error & 47 & 4.814 & 0.1024 & & \\
\hline Total & 49 & 70.590 & & & \\
\hline
\end{tabular}

${ }^{a} \mathrm{DF}$-degrees of freedom, ${ }^{\mathrm{b}} \mathrm{Adj}$. SS-adjusted sums of squares, ${ }^{\mathrm{C} A d j .}$ MS—adjusted mean squares

Kruskal-Wallis test. This was performed to verify the equality of the averages of the flame speeds of the materials returning $p$ values for $\mathrm{G} 2(p=2.62019 \mathrm{E}-05), \mathrm{G} 3$ $(p=0.000)$ and $\mathrm{G} 4(p=0.000)$. In this way, the alternative hypothesis was accepted at a significance level $a=0.05$ considering that there is difference in the flame speeds between the group of materials.

In order to determine the best condition, which is evidenced by the lowest average for the flame speed, the multiple comparisons test, proposed by Hsu [39], was performed with the best results and demonstrated the difference between each average flame speed with the best of averages. The confidence interval for the material with the lowest average flame speed for each group of exploratory variables, which presents a large part of the negative values, is the best among the others. Table 5 presents the results of multiple comparisons test.

In this way, the results of Hsu's multiple comparisons test confirm the previously statistical analysis.

In order to facilitate the visualization of the various analyses of the three explanatory variables ("direction," "material" and "weave") with the response variable "flame speed," by grouping the results from the physical tests performed on the fabrics with specific affinities, i.e., similar technical specifications, the summarized values are expressed in Table 6.

The explanatory variable "direction" presents two levels: filling and warp. The behavior of the explanatory variable "direction" on the response variable "flame speed" resulted in statistically equal values for filling and warp for the material groups: "100\% CO, twill weave"; "67\% PES/33\% CO, twill weave"; "67\% PES/33\% CO, plain weave"; and "50\% WO/50\% PES, plain weave" (Table 6).

For the groups corresponding to polyester material "100\% PES, twill weave," the value for "flame speed" was lower in the warp direction. For the "100\% PES, plain weave," the lowest velocity was observed in the direction of the filling. This result can be explained by the higher linear density of the filling yarn $(13.67 \pm 0.54$ Tex), slightly smaller weight and higher number of yarns for the " $100 \%$ PES, plain weave."

The results for the explanatory variable "material" on the response variable "flame speed" resulted in statistically equal values for filling and warp for: " $100 \%$ CO, twill weave"; "67\% PES/33\% CO, twill weave"; "67\% PES/33\% CO, plain weave"; and " $50 \%$ WO/50\% PES, plain weave."

After grouping, the explanatory variable "material" presented three levels: $100 \%$ CO; $100 \%$ PES; and $67 \%$ PES $/ 33 \%$ $\mathrm{CO}$. For the "plain weave, filling direction" group, the average flame speed was equal for "100\% PES" and " $67 \%$ $\mathrm{PES} / 33 \% \mathrm{CO}$ " materials.

In Table 6, the results for the "twill weave, filling direction" and "twill weave, warp direction" groups presented different results for "flame speed" averages for "100\% CO," "100\% PES" and " $67 \%$ PES/33\% CO" materials. The material with the lowest "flame speed" value was " $100 \%$ CO" and then " $67 \%$ PES $/ 33 \%$ CO." Such behavior can be explained by the mixing of cotton fibers with polyester fibers.

The values obtained in the present study, expressed in "flame speed" response variable by explanatory variables ("direction," "material" and "weave"), cannot be compared directly with another ones in the literature, since they depend on the employed equipments and methodologies as well as the textile material kind and size of specimens, which may vary widely from study to study.

However, limiting oxygen index (LOI) values enable an indirect comparison of intrinsic flame resistance of the different fiber types, independent of other factors. Table 7 presents LOI values for the most used fibers in the preparation of uniforms, such as cotton, wool, silk and polyester. These values support the results and conclusions of the present study.

Thus, taking in account natural fibers, wool presents the best burning resistance with a $\mathrm{LO}$ of $25 \%$. Its flame-retardant activity can be associated with the protein chemical composition of fibers, in which nitrogen is present. This element 
G1
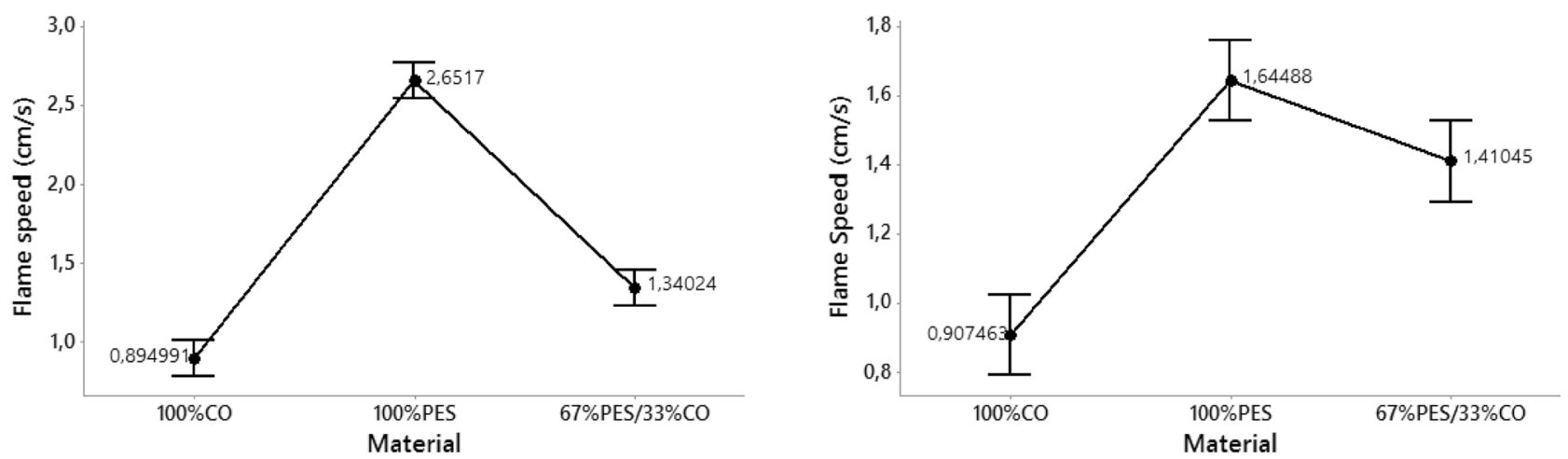

G3
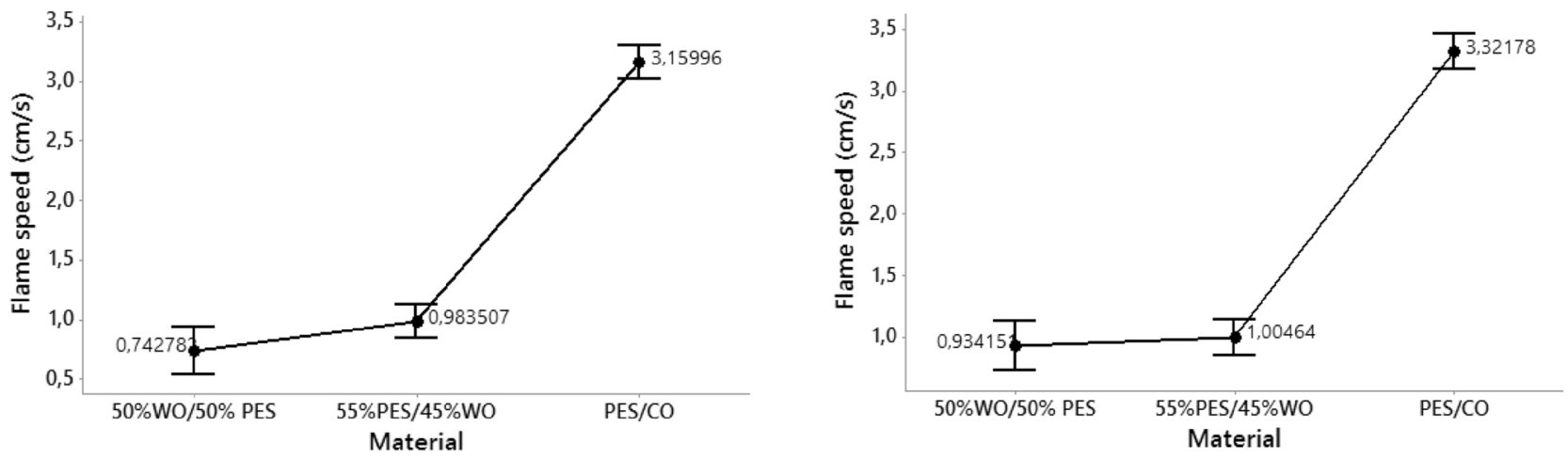

Fig. 5 Interval plot of flame speed vs. material: G1 (twill weave, filling direction), G2 (twill weave, warp direction), G3 (plain weave, filling direction) and G4 (plain weave, warp direction), all of them with $95 \%$ confidence interval

Table 5 Flame speed comparison through multiple comparisons test

\begin{tabular}{|c|c|c|c|c|c|c|c|}
\hline \multicolumn{4}{|c|}{ Explanatory variables groups } & \multirow{2}{*}{$\begin{array}{l}\text { ANOVA } \\
0.000\end{array}$} & \multicolumn{2}{|c|}{ Validation $p$ value } & \multirow{2}{*}{$\begin{array}{l}\text { Lesser flame speed } \\
100 \% \text { CO }\end{array}$} \\
\hline Weave & Twill & Direction & Filling & & 0.115 & Material & \\
\hline & Twill & & Warp & 0.000 & 0.054 & & $100 \% \mathrm{CO}$ \\
\hline & Plain & & Filling & 0.000 & $>0.005$ & & $50 \% \mathrm{PES} / 50 \% \mathrm{WO}$ \\
\hline & Plain & & Warp & 0.000 & $>0.005$ & & $50 \%$ PES/50\%WO \\
\hline
\end{tabular}

is characterized as nonflammable and does not support combustion. In this way, there is slow propagation of the flames, i.e., the burning becomes slow. According to the LOI values (Table 7), only taking into account the flammability issue, fibers like silk and wool, from animal origin, can be employed as suitable textile materials for uniforms. Furthermore, protein fibers exhibit excellent moisture absorption, antistatic behavior, comfort in almost all environmental conditions and aesthetic qualities, desired characteristics for the development of uniforms.

\section{Conclusion}

The explanatory variable "material" was grouped in five levels: (1) 100\% CO; (2) 100\% PES; (3) 67\% PES/33\% CO; (4) $50 \% \mathrm{PES} / 50 \% \mathrm{WO}$; and (5) $55 \% \mathrm{PES} / 45 \%$ WO. The 


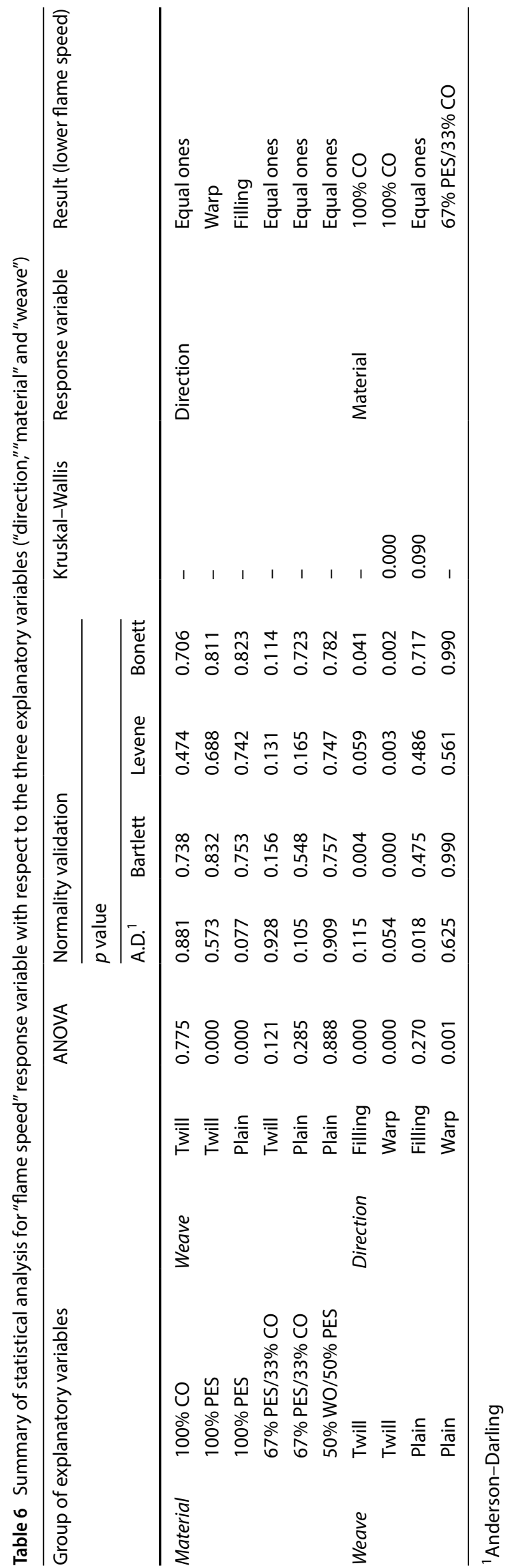

Table 7 Limiting oxygen index (LOI) data for natural and manmade fibers [8]

\begin{tabular}{lll}
\hline Fiber & LOI & Classification \\
\hline Flax & 17.4 & \\
Cotton & 18.4 & LOI $<20.95$ \\
Polyester & $20.0-21.0$ & Flammable \\
Silk & 23.0 & $21<$ LOI $<28$ \\
Wool & 25.2 & Slow burning \\
\hline
\end{tabular}

test of the material " $50 \% \mathrm{PES} / 50 \%$ WO, plain weave and filling direction" presented the lowest flame speed $(0.742 \pm 0140 \mathrm{~cm} / \mathrm{s})$. At the other extreme, the highest value was $3.698 \pm 1.806 \mathrm{~cm} / \mathrm{s}$ for the material "67\%PES/33\%CO, plain weave and filling direction."

These values were obtained for the test of a masculine trousers (the smallest value) and masculine shirt (the highest value), being materials already used in the manufacture of some uniforms, accessible to the development of new collections. Such care, i.e., to consider a material with a lower flame speed, means for professionals trained to fight fire on board, take time to remove a burning garment, maintain their physical integrity and continue to fulfill their duties as security agents on board at the end of the event.

It is possible to think of future experiments for reducing the flammability of the uniforms' fabrics of the aeronauts and other professionals, taking into account the combination of characteristics of the textile material, such as:

1. More closed fabric constructions, with minimum distance between the threads, increasing the cover factor and decreasing the oxygen that circulates in the interstices of the fabric;

2. Construction of natural fiber fabrics from vegetal or animal origin or mixtures with synthetic fibers to add functionality, such as flame-retardant additives. The tests demonstrated that the flame speed response is not proportional to the different proportion of fibers;

3. Changing the direction of the fabric employed in the preparation of the uniforms, since the flame speed is smaller in the direction of the weft. Thus, variations in the modeling of clothing (e.g., straight or bias cut) could be related to some change in the flammability (flame speed) of the uniform. Still a better studied model (besides the aesthetic question) could help to protect the body of the aeronauts of possible accidents involving flammability;

4. To study changes in the weight and torsion of its constituent yarns, since the composition of the fabrics is 
dependent on these variables, which contribute to the mass of fuel available for burning.

Acknowledgements The authors gratefully acknowledge the funding by São Paulo Research Foundation-FAPESP ("Fundação de Amparo à Pesquisa do Estado de São Paulo") Grant Number 2016/01331-9.

\section{Compliance with ethical standards}

Conflict of interest The authors declare that they have no conflict of interest.

\section{References}

1. Lewin M (1985) Handbook of fiber science and technology volume 2: chemical processing of fibers and fabrics-functional finishes. Marcel Dekker INC, New York

2. Sinclair R (2015) Textile and fashion: materials, design and technology. Woodhead Publishing Limited Abington Hall, Cambridge

3. Bourbigot $S$ (2008) Flame retardancy of textile: new approaches. In: Horrocks R, Price D (eds) Advances in fire retardant materials. Woodhead Publishing Limited Abington Hall, Cambridge, p 625

4. Grover T, Khandual A, Luximon A (2014) Fire protection: flammability and textile fibres. Colourage. https://www.researchga te.net/publication/287938487_Fire_protection_Flammabili ty_and_textile_fibres Accessed 30 May 2019

5. Fan J, Lau L (2009) Flammability of fabrics and garments. In: Fan J, Hunter L (eds) Engineering apparel fabrics and garments. Woodhead Publishing Limited Abington Hall, Cambridge, p 413

6. Pan Y, Liu L, Wang X, Song L, Hu Y (2018) Hypophosphorous acid cross-linked layer-by-layer assembly of green polyelectrolytes on polyester-cotton blend fabrics for durable flame-retardant treatment. Carbohydr Polym. https://doi.org/10.1016/j.carbp ol.2018.08.044

7. Galaska ML, Horrocks AR, Morgan AB (2017) Flammability of natural plant and animal fibers: a heat release survey. Fire Mater. https://doi.org/10.1002/fam.2386

8. Silva-Santos MC, Oliveira MS, Giacomin AM, Laktim MC, BaruqueRamos J (2017) Flammability on textile of business uniforms: use of natural fibers. Procedia Eng. https://doi.org/10.1016/j.proen g.2017.07.022

9. Bilir MZ, Gürcüm BH (2018) Ballistic wearable electronic vest design. J Ind Text. https://doi.org/10.1177/1528083717710710

10. Daniel MH (2018) Guia prático dos tecidos ("Practical Guide of Fabrics"). Novo Século Editora, Barueri

11. Weil ED, Levchik SV (2008) Flame retardants in commercial use or development for textiles. FIRE Sci. https://doi. org/10.1177/0734904108089485

12. Lord PR (2003) Handbook of yarn production: technology, science and economics. Woodhead Publishing Limited Abington Hall, Cambridge

13. Venter MP, Venter G (2018) Simple implementation of plain woven polypropylene fabric. J Ind Text. https://doi. org/10.1177/1528083716665627

14. Yang CQ, He Q, Lyon RE, Hu Y (2010) Investigation of the flammability of different textile fabrics using micro-scale combustion calorimetry. Degrad Stab, Polym. https://doi.org/10.1016/j. polymdegradstab.2009.11.047
15. Rogina-Car B, Budimir A, Katovic D (2017) Microbial barrier properties of healthcare professional uniforms. Text Res J. https://doi. org/10.1177/0040517516659383

16. Timmons S, East $L$ (2011) Uniforms, status and professional boundaries in hospital. Sociol Heal Illn. https://doi.org/10.111 1/j.1467-9566.2011.01357.x

17. Ugolini L (2010) Consumers to combatants? British uniforms and identities, 1914-18. Fash Theory. https://doi.org/10.2752/17517 $4110 \times 12665093381540$

18. ABNT NBR NM ISO 3758:2013-Textiles-care labelling code using symbols. Brazilian Association of Technical Standards, Rio de Janeiro

19. Thermo Electro Co. (2004) Nicolet FT-IR User's Guide. https:// instrumentalanalysis.community.uaf.edu/files/2013/01/FT-IR_ manual.pdf Accessed 30 May 2019

20. ABNT NBR 12996:1993-Textile material-determination of basics weaves-methods of test. Brazilian Association of Technical Standards, Rio de Janeiro

21. NP 4114:1991-Textile-woven fabrics - construction - methods of analysis-presentation of a weave diagram and plans for drafting, denting and lifting. Portuguese Institute of Quality, Lisboa

22. ISO 7211-1:1984-Textiles-woven fabrics - constructionmethods of analysis- Part 1: methods for the presentation of a weave diagram and plans for drafting, denting and lifting. International Organization for Standardization, Geneva

23. ABNT NBR 10588:2015-Woven-determination of density yarn. Brazilian Association of Technical Standards, Rio de Janeiro

24. ISO 7211-2:1984-Textiles-woven fabrics-constructionmethods of analysis-part 2: determination of number of threads per unit length. International Organization for Standardization, Geneva

25. ABNT NBR 13371:2005-Textiles materials-determination of thickness. Brazilian Association of Technical Standards, Rio de Janeiro

26. ABNT NBR ISO 139:2008-Textiles-standard atmospheres for conditioning and testing. Brazilian Association of Technical Standards, Rio de Janeiro

27. ABNT NBR 12331:1991-Textile fibers-conditioning conventional rate-standardization. Brazilian Association of Technical Standards, Rio de Janeiro

28. ISO 7211/5:1984-Textiles-woven fabrics-constructionmethods of analysis - Part 5: determination of linear density of yarn removed from fabric. International Organization for Standardization, Geneva

29. ISO 7211/3:1984 Textiles-woven fabrics-construction-methods of analysis-Part 3: determination of crimp of yarn in fabric International Organization for Standardization, Geneva

30. ISO 7211/4:1984 Textiles-woven fabrics-construction-methods of analysis - part 4: determination of twist in yarn removed from fabric. International Organization for Standardization, Geneva

31. Behera BK, Hari PK (2010) Woven textile structure-theory and applications. Woodhead Publishing Limited Abington Hall, Cambridge

32. Maluf E, Kolbe W (2003) Dados Técnicos para a Indústria Têxtil ("Technical Data for the Textile Industry"). 2nd ed. IPT - Instituto de Pesquisas Tecnológicas do Estado de São Paulo and ABITAssociação Brasileira da Indústria Têxtil e de Confecção, São Paulo

33. Kaswell ER (1963) Wellington sears handbook of industrial textiles. Massachusetts Institute of Technology (MIT) and Wellington Sears Company, Cambridge

34. E-CFR (2019) PART 1610-Standard for flammability of clothing textile. https://gov.ecfr.io/cgi-bin/text-idx?SID=3d3c0fb9f5 
f6008e702092e89327aa5e\&mc=true\&node=pt16.2.1610\&rgn $=$ div5 Accessed 30 May 2019

35. ISO 6940:2004-Textile fabrics-burning behavior-determination of ease of ignition of vertically oriented specimens. International Organization for Standardization, Geneva

36. ISO 6941:2003-Textile fabrics-burning behavior-measurement of flame spread properties of vertically oriented specimens. International Organization for Standardization. Geneva

37. NF G07-182:1985-Textiles-fire behavior-measurement of flame spread properties of 45 degrees oriented specimensdetermination of flame spread rate. French Association of Normalization, Paris
38. Magalhães MN, Lima ACP (2015) Noções de probabilidade e estatística ("Notions of Probability and Statistics"). EDUSP, São Paulo

39. Minitab Inc (2000) Minitab User's Guide 2: Data Analysis and Quality Tools. https://shamsulsarip.files.wordpress. com/2015/07/minitab_book.pdf Accessed 30 May 2019

Publisher's Note Springer Nature remains neutral with regard to jurisdictional claims in published maps and institutional affiliations. 